\title{
Punch Multi-slice Longwall Mining System for Thick Coal Seam under Weak Geological Conditions
}

\author{
Takashi Sasaoka ${ }^{1}$, Akihiro Hamanaka ${ }^{1}$, Hideki Shimada ${ }^{1}$, Kikuo Matsui ${ }^{1}$, Nay Zar $\operatorname{Lin}^{2}$ and Budi Sulistianto ${ }^{3}$ \\ 1. Department of Earth Resources Engineering, Kyushu University, Fukuoka 819-0395, Japan \\ 2. Mine Planning Section, Ministry of Mines, Nay Pyi Taw, Myanmar \\ 3. Department of Mining Engineering, Institute Technology Bandung, Bandung 40116, Indonesia
}

\begin{abstract}
Most of coal is produced from open-cut mines in Southeast Asian countries. However, the conditions of their surface mines are worsening each year: the stripping ratio is increasing, approaching economic ratio and the regulation of environmental protection. To meet the demand for coal, underground mines have to be developed in the near future. Under these circumstances, the development of new coal mines from open-cut highwalls are being planned in Southeast Asian Countries. Moreover, some of the Southeast Asian mines have thick coal seams. However, if the conventional mining systems and designs introduced in US, Australia and European Countries are applied, several geotechnical issues can be expected due to the mines' weak geological conditions. From these backgrounds, this paper proposed a punch multi-slice mining system with stowing for thick coal seam under weak geological conditions and discussed its applicability and suitable design by means of numerical analysis.
\end{abstract}

Key words: Punch multi-slice longwall mining, thick coal seam, weak strata, stability of highwall.

\section{Introduction}

The surface mining method is generally considered to be more advantageous than the underground method, especially in recovery, grade control, production capacity, economics, flexibility, safety and working environments. Therefore, the surface mining method is common in major coal producing countries [1, 2]. Most of coal is produced from open-cut mines in Southeast Asian countries. However, the conditions of their surface mines are worsening each year: the stripping ratio is increasing, approaching economic ratio, the regulation of environmental protection, and poor infrastructure for coal from inland mining areas [3]. To meet the demand for coal in Southeast Asian Countries and the rest of the world, underground mines have to be developed in the near future. Under these circumstances, the development of new coal mines from open-cut highwalls are being planned in several

Corresponding author: Takashi Sasaoka, assistant professor, research fields: ground control in mining, blasting and mining system. E-mail: sasaoka@mine.kyushu-u.ac.jp. mines in Southeast Asian Countries including Thailand, Indonesia, etc. Moreover, some of the Southeast Asian mines have thick coal seams [4, 5]. However, if the conventional mining systems and designs introduced in US, Australia and European Countries are applied, several geotechnical issues can be expected due to the mines' weak geological conditions [6]. From these backgrounds, a punch multi-slice top coal caving method with stowing was proposed as a mining system for thick coal seam and weak geological conditions.

This paper discusses the applicability of punch multi-slice top coal caving method to the mines in South-East Asian Countries and its suitable design and measures by means of numerical analysis.

\section{Punch Mining System}

One of the major mining system for final highwall of surface coal mine is highwall mining system. Conventional highwall mining systems extract coal with an auger machine or continuous miner. However, less coal recovery is a problem in these systems, 
because many coal pillars have to be left in order to maintain the highwall/mined openings stability and the mined length is limited by the inherent characteristics of the systems. Considering these issues, the introduction of underground mining systems is also an alternative. The punch mining system is not a new concept [7]. The first punch mining system using an Archveyor system was proposed and tried in the US as shown in Fig. 1. However, this mining system has to leave a lot of coal as pillars.

Rapid access punch longwall mining has been practiced in Australia. Australia's first punch longwall mining operation commenced in the late 1990s using conventional longwall equipment to mine coal from blocks developed directly from an open-cut final highwall [8]. Fig. 2 shows the schematic of punch longwall mining system.

Beltana is a highwall access longwall punch mine, which achieved its first full year of operation in 2004, producing 6 Mt (ROM: Run-of-Mine) coal. It is considered to be the most cost-efficient longwall operation in Australia [9]. The advantages in this system of mining are: high productivity; the system requires no transport, conveyor drifts, shafts, complex ventilation systems or main headings as in conventional

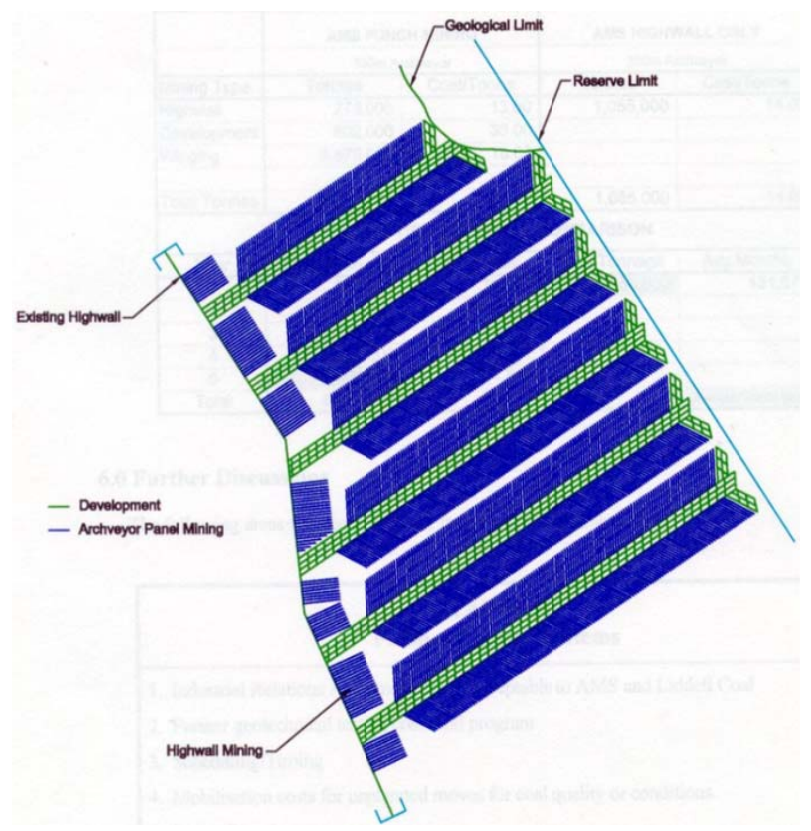

Fig. 1 Punch mining system.

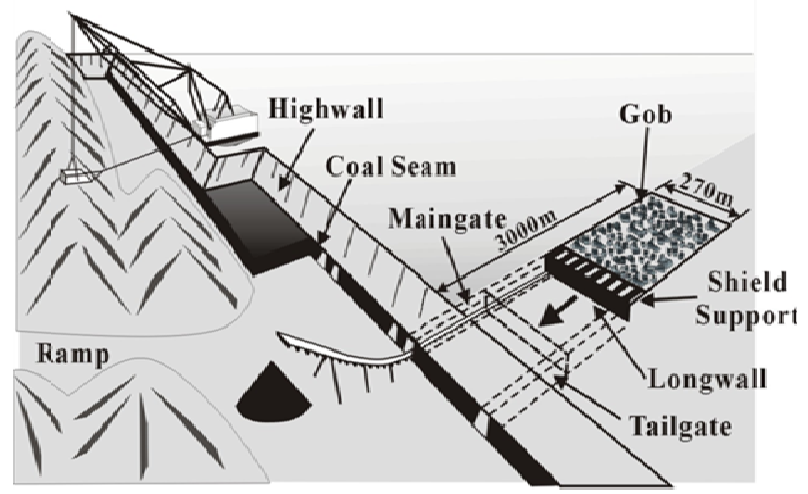

Fig. 2 Punch longwall mining system.

underground mining methods, hence this benefit provides cheaper, faster, simpler access and commencement of longwall mining. However, it is required proper mine planning and mine design to retain and maintain the open cut surface infrastructure throughout the life of underground operations. Due to its advantages of high production capacity and productivity, and competitively lower cost than highwall mining system, this system is expected to be increasingly implemented in Australian coal mines. However, the design and the ground behavior around the mining panel/face and its impact of the stability of slope and the mining operation in weak geological condition have not been made clearly.

\section{Multi-slice Top Coal Caving Method with Stowing}

While considering the situation of Southeast Asian mines, an applicability of highwall mining systems are less potential due to their limitations in penetration lengths. It is seen that punch highwall mining systems may be considered for the mines. However, as for extraction of the thick coal seam, it must be mined by dividing the seams into multi-slicing. However, when multi-slicing method is applied, the ground behavior around the mining panel/face and their impact of the stability of slope and the mining operation have not been made clearly yet. In case, the ground control issues such as highwall instability can be expected if a conventional thick seam mining method is introduced. 
A new multi-slice top coal caving mining method based on the concept of punch longwall and top coal caving methods is proposed. The concept of the new multi-slice top coal caving mining method is illustrated in Fig. 3. First, the coal seam is developed along the mine roof with conventional cut. Then stowing material is injected into gob area in order to have better mine roof condition. After the stowing material is consolidated, the next slice is begun by leaving appropriate thickness of coal parting beneath the first slice and it is recovered by applying a top coal caving method in the second slice. After the second slice is extracted using a top coal caving method, stowing material is injected into the gob area in the second slice. Next slices are also extracted by applying a top coal caving method and stowing is conducted after each slice is mined out and mining and stowing are repeated until the whole coal seam is mined out as the same manner. By applying this method, the number of slices required for the extra-thick coal seam and the burden for excessive costs for development of gate roads required for extra-thick seam can also be overcome compared with an application of the conventional multi-slice mining method. It will be also useful to reduce the impact on ground/slope due to extraction of extra-thick coal seams and can also be useful to minimize the amount of waste rocks managed on surface.

\section{Numerical Analysis}

When an underground mine is developed from an open-cut highwall, the design of panels and safety pillars such as boundary pillar and inter-panel pillar in the transition area have great influenced on the highwall stability as well as the amount of resource recovery around the final highwall. If the pillar and panel sizes are inadequate, it is possible for slope instability or sliding of slope due to insufficient support to the highwall. On the other hand, if the pillars are over-sized, the amount of resource recovery around the highwall will be decreased. Therefore, careful planning and designing of panels and pillars around the final highwall. In order to make the criteria for the applicability and the design of a punch multi-slice top coal caving method around the final highwall, the response of ground/slope under weak geological conditions and different operational conditions are investigated by means of FLAC3DVer.5.

\subsection{Numerical Model}

In surface mining, as the bench design is usually based on economic reach of the mining equipment used in the mine, characteristics of deposit, production strategy and geological and geotechnical condition of the mine. In this study, therefore, the following assumptions are made based on the typical bench design for open-cut coal mining practices [10]. The height of the each single bench is designed as $20 \mathrm{~m}$, and the bench slope angle is 65 degrees. The width of the bench is set as $36 \mathrm{~m}$ whereas the safety berm is $6 \mathrm{~m}$ wide in the models. The angle of overall slope is 37 degrees. The geometry, meshes and group of zones and dimension of the $200 \mathrm{~m}$ deep pit model employed in the analyses are illustrated in Fig. 4. In this study, mechanical properties of rock obtained from one Indonesian surface coal mine are used in this study as represented in Table 1.

The design of panels and pillars in transition area from surface to underground mine for thick seam under weak and strong geological condition are discussed. Due to the advantages of highest efficiency

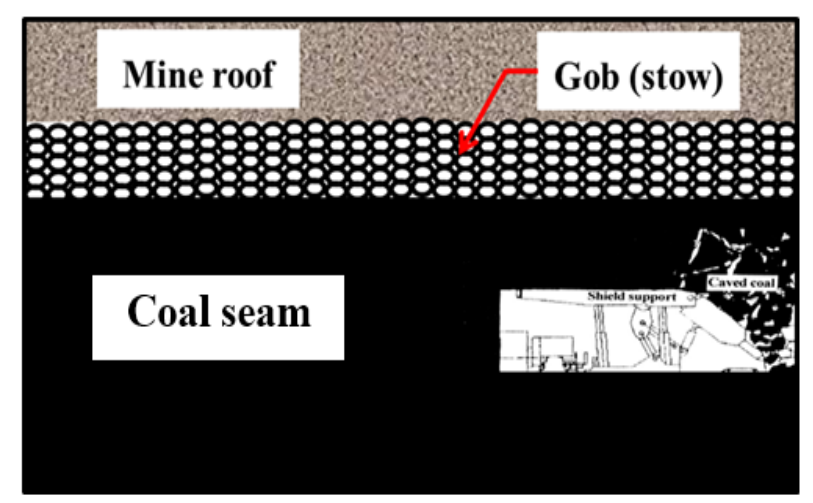

Fig. 3 Concept of multi-slice top coal caving with stowing method (longwall mining system). 


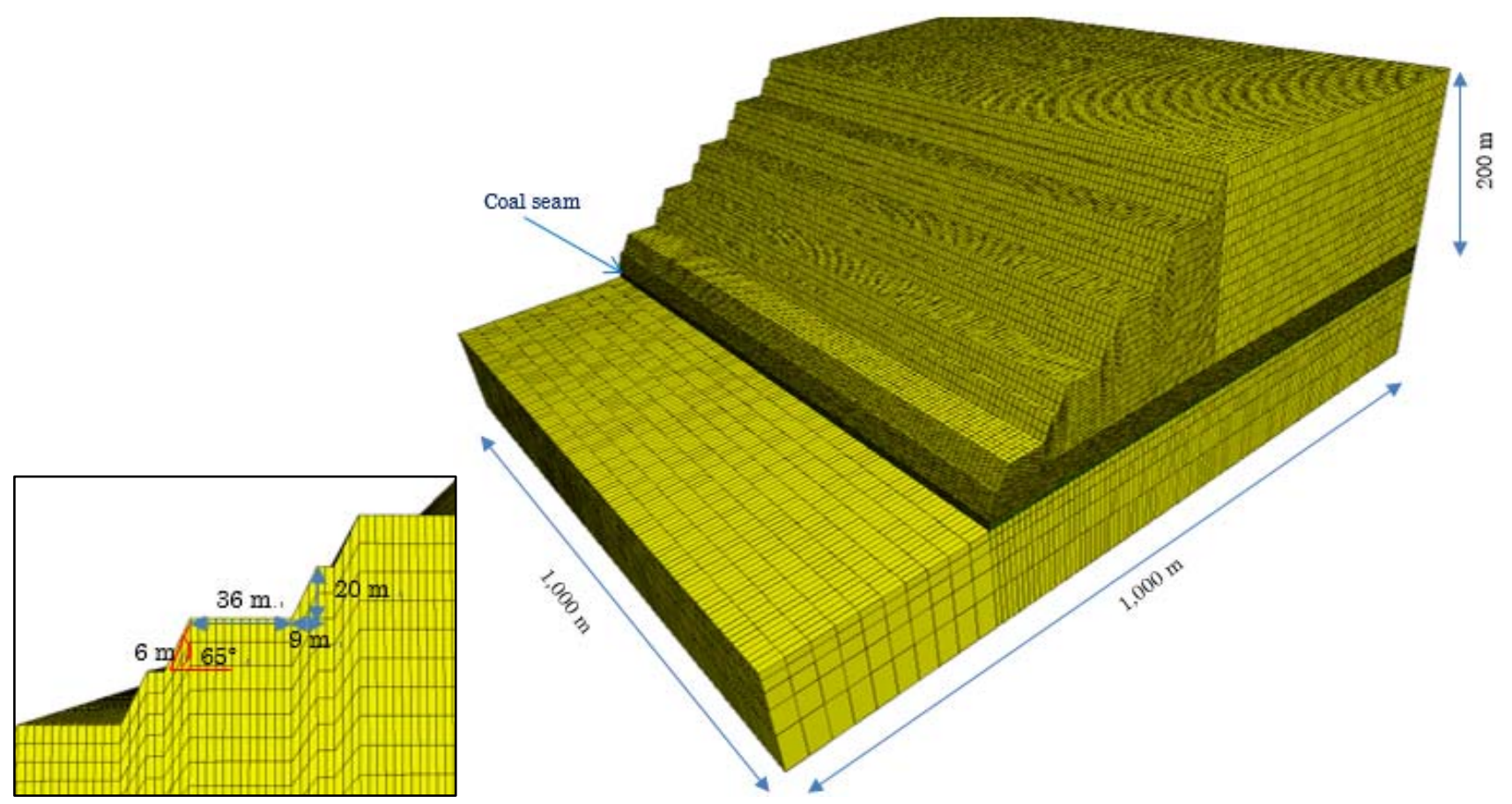

Fig. 4 Numerical model (Pit depth $=200 \mathrm{~m})$.

Table 1 Mechanical properties of rock mass and coal used in this analyses.

\begin{tabular}{lll}
\hline & Rock mass & Coal \\
\hline Density $\left(\mathrm{kg} / \mathrm{m}^{3}\right)$ & 1,950 & 1,430 \\
UCS (Uniaxial compressive & 11.36 & 5.0 \\
strength) (MPa) & $6.67 \times 10^{3}$ & $3.79 \times 10^{2}$ \\
Bulk modulus (MPa) & $4.0 \times 10^{4}$ & $1.95 \times 10^{2}$ \\
Shear modulus (MPa) & 0.1 & 0.1 \\
Tensile strength (MPa) & 1.75 & 0.5 \\
Cohesion (MPa) & 25 & 22.3 \\
Friction angle (deg.) & \\
\hline
\end{tabular}

and productivity among the methods available for thick seam, a longwall top coal caving method is primarily considered in this study. In longwall top caving practices, although the method allows for more than 10 m thick seam in one pass and up to $80-90 \%$ recovery of additional coal, coal recovery is less than expected in practical situation due to coal seam and strata conditions, about $70-80 \%$ of coal can be recovered in practical situation. Operational issues also limit top coal recovery and can often account for a greater percentage of the reduce recovery than geological conditions alone. In this study, therefore, two slice system is considered for the $10 \mathrm{~m}$ thick coal seam, where the first slice is cut conventionally and next slice is extracted by top coal caving method. Basically, the height of mining for conventional cut for the first slice was considered as $3 \mathrm{~m}$ and next slice is set as $7 \mathrm{~m}$, where $3 \mathrm{~m}$ thick of coal is cut along the floor of coal seam and $4 \mathrm{~m}$ thick of coal is recovered. The scheme of multi-slice top coal caving mining method performed in the analyses is illustrated in Figs. 5a-5b.

The panels and pillars were initially designed based on the results of preliminary analysis that the conventional longwall mining system is applied for the extraction of $3 \mathrm{~m}$ thickness of coal under weak geological condition. The panel of $100 \mathrm{~m}$ width and the inter-panel pillar of $60 \mathrm{~m}$ width are initially taken and the ground behavior is investigated. The boundary pillar of $100 \mathrm{~m}$ width for $200 \mathrm{~m}$ and $300 \mathrm{~m}$ deep pit and that of $150 \mathrm{~m}$ width for $400 \mathrm{~m}$ deep is initially taken. Layout of the initial mining panel is shown in Fig. 6.

\subsection{Results and Discussions}

4.2.1 Punch Multi-slice Longwall Mining System without Stowing System

Figs. 7a-7b and 8a-8b show failure states and contours of induced displacement after extracting second slice in 


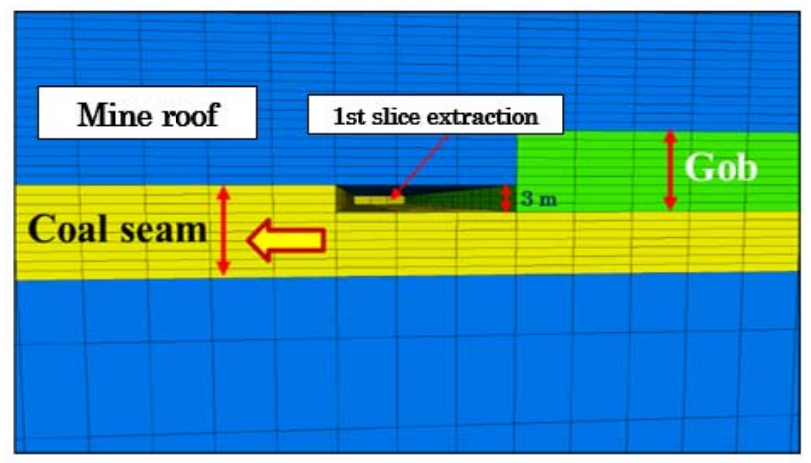

(a) The First slice extraction

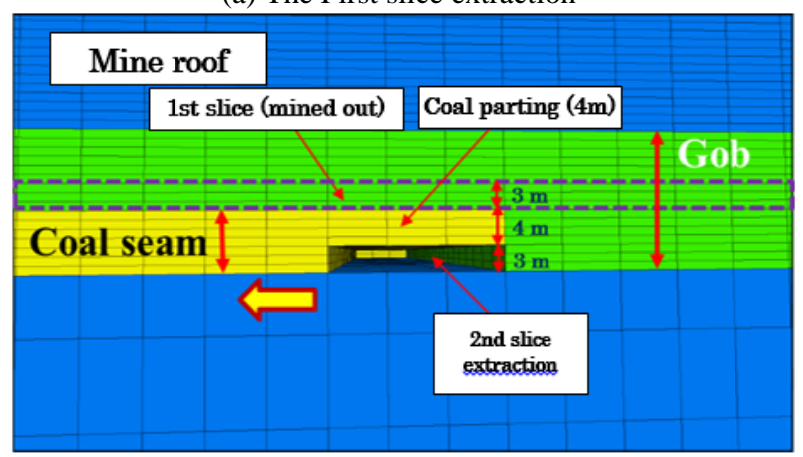

(b) The second slice extraction

Fig. 5 Scheme of multi-slicing performed in the analyses (without stowing).

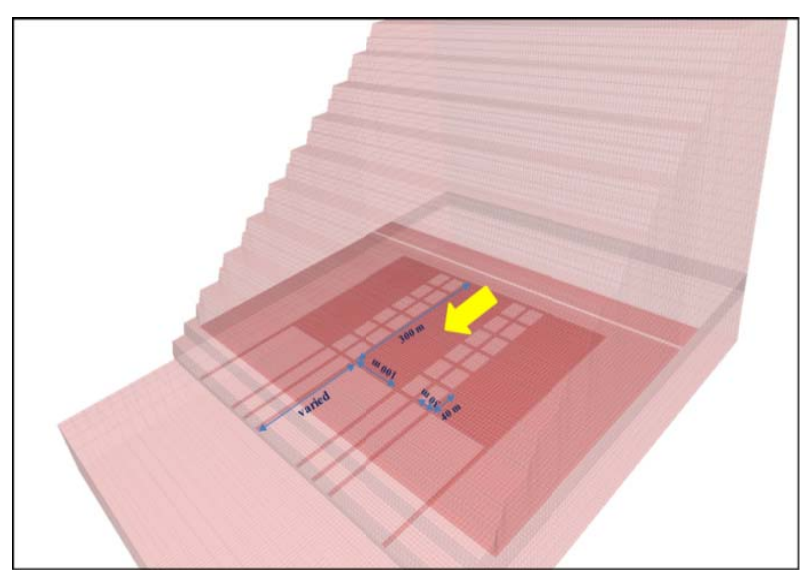

Fig. 6 Layout of panel modelled in the analyses.

$200 \mathrm{~m}$ and $300 \mathrm{~m}$ deep pit slopes, respectively. In the case of $200 \mathrm{~m}$ pit depth, as the displacement at the slope is observed $6.5-7 \mathrm{~cm}$ in maximum and the boundary pillar is also in stable condition. Therefore, it can be said that the stability of overall slope can be maintained under these panel and pillar designs. On the other hand, in the cases of $300 \mathrm{~m}$ pit depth, even though the vertical displacement at the slopes is about $6.5-7 \mathrm{~cm}$ in both cases, large failures are occurred at the boundary pillars. In this situation, if the condition at the toe of the slope is worsen and the pillar is failed, the whole slope instability and/or slide would be occurred. Consequently, the widths of boundary pillars are increased into $200 \mathrm{~m}$ in the cases that the pit depth is larger than $300 \mathrm{~m}$.

Figs. 9a-9b and 10a-10b show the failure states and contours of displacement in the cases of $300 \mathrm{~m}$ and 400 $\mathrm{m}$ deep pits. In the case of $300 \mathrm{~m}$ deep pit depth, the condition of boundary pillar can be improved and the slope can be maintained. On the other hand, in the case of $400 \mathrm{~m}$ deep pit, as the boundary pillar is still failed and the large displacement can be recognized in the slope, the stability of overall slope still cannot be maintained. Therefore, the ground behavior by modeling with larger inter-panel pillar and smaller panel width is discussed in the case of $400 \mathrm{~m}$ pit depth.

The width of inter-panel pillar is increased from 60 $\mathrm{m}$ to $100 \mathrm{~m}$ and the width of panel is decreased from $100 \mathrm{~m}$ to $60 \mathrm{~m}$. Fig. 11 illustrates the layout of panel and Figs. 12a-12b shows the failure states and contours of displacement in this conditions. It is found that the displacement at the slope is decreased from $4.5-5 \mathrm{~cm}$
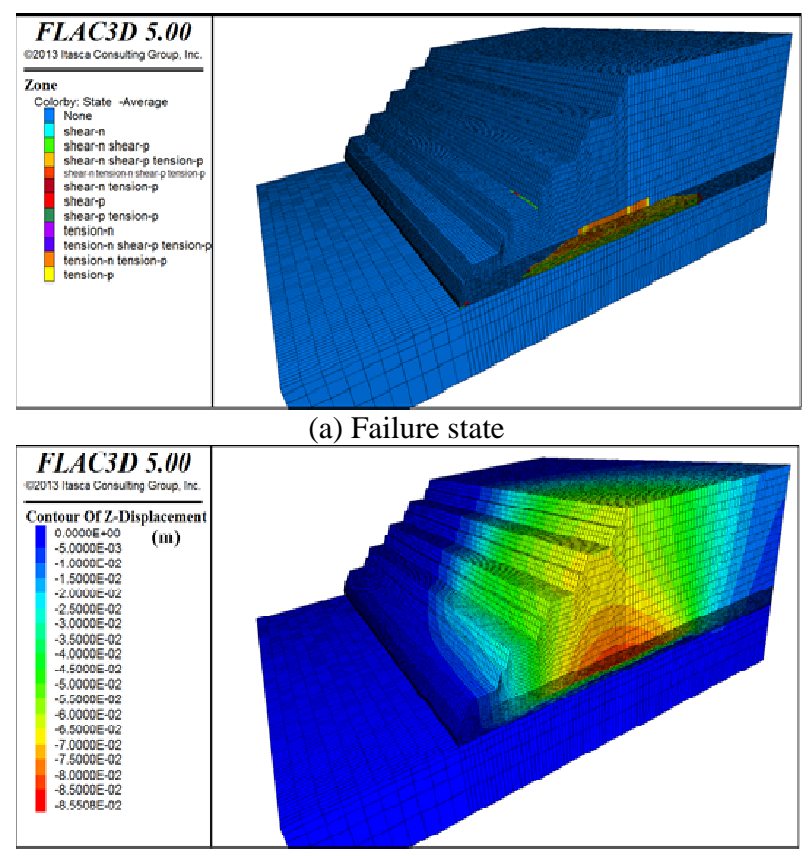

(b) Displacement

Fig. 7 Failure states and contours of displacement after extracting 2nd slices in $200 \mathrm{~m}$ deep pit slope (boundary pillar width $=100 \mathrm{~m}$, inter-panel pillar width $=60 \mathrm{~m}$, panel width $=100 \mathrm{~m}$ ). 


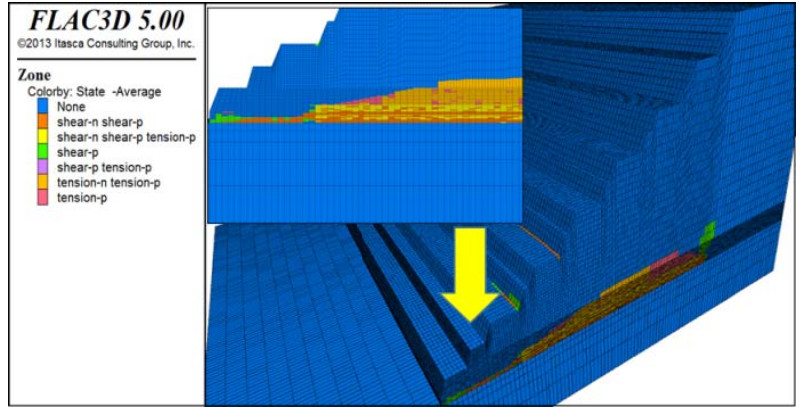

(a) Failure state

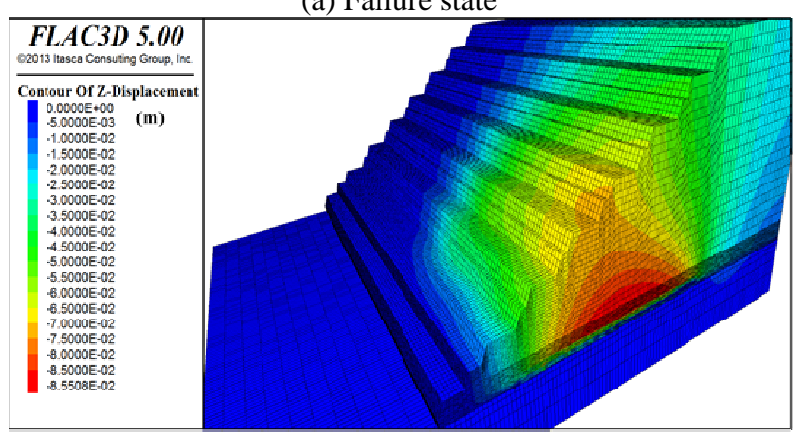

(b) Displacement

Fig. 8 Failure states and contours of displacement after extracting 2nd slices in $300 \mathrm{~m}$ deep pit slope (boundary pillar width $=100 \mathrm{~m}$, inter-panel pillar width $=60 \mathrm{~m}$, panel width $=100 \mathrm{~m}$ ).

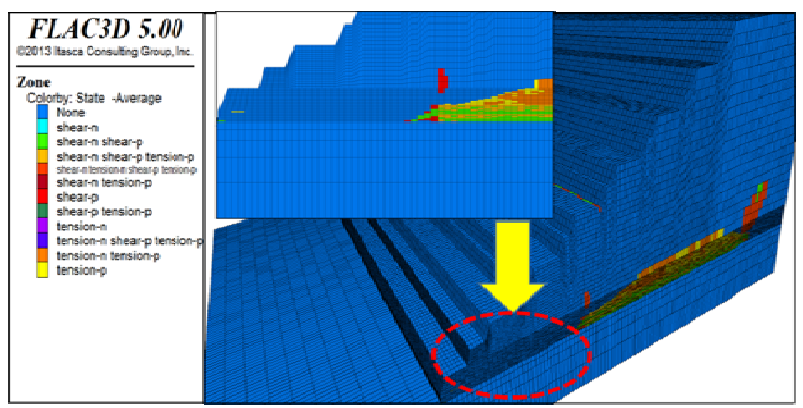

(a) Failure state

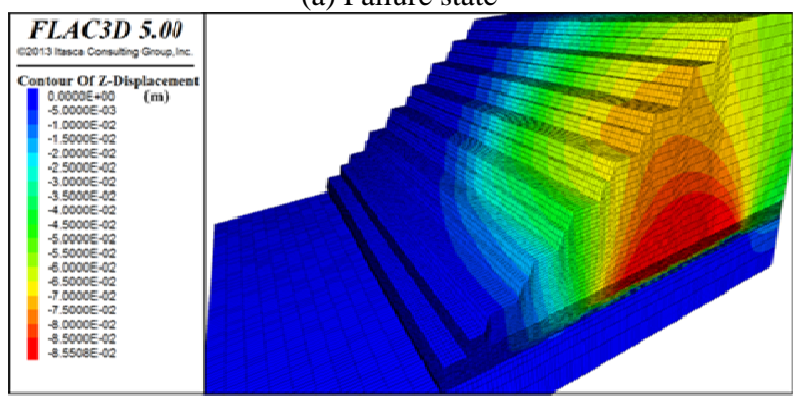

(b) Displacement

Fig. 9 Failure states and contours of displacement after extracting 2nd slices in $300 \mathrm{~m}$ deep pit slope (boundary pillar width $=200 \mathrm{~m}$, inter-panel pillar width $=60 \mathrm{~m}$, panel width $=100 \mathrm{~m})$.

into 3.5-4 cm. In addition, the failure condition of boundary pillar is improved and its stability can be maintained. However, a plenty of coal have to be left in order to maintain the stability of slope in the case of 400 m deep pit.

\subsubsection{Application of Stowing System}

According to the results discussed above, it is found that punch multi-slice top coal caving method can also be applicable around the final highwall by a proper panel and pillar design. However, since the large amount of coal have to be left as the pillars, coal
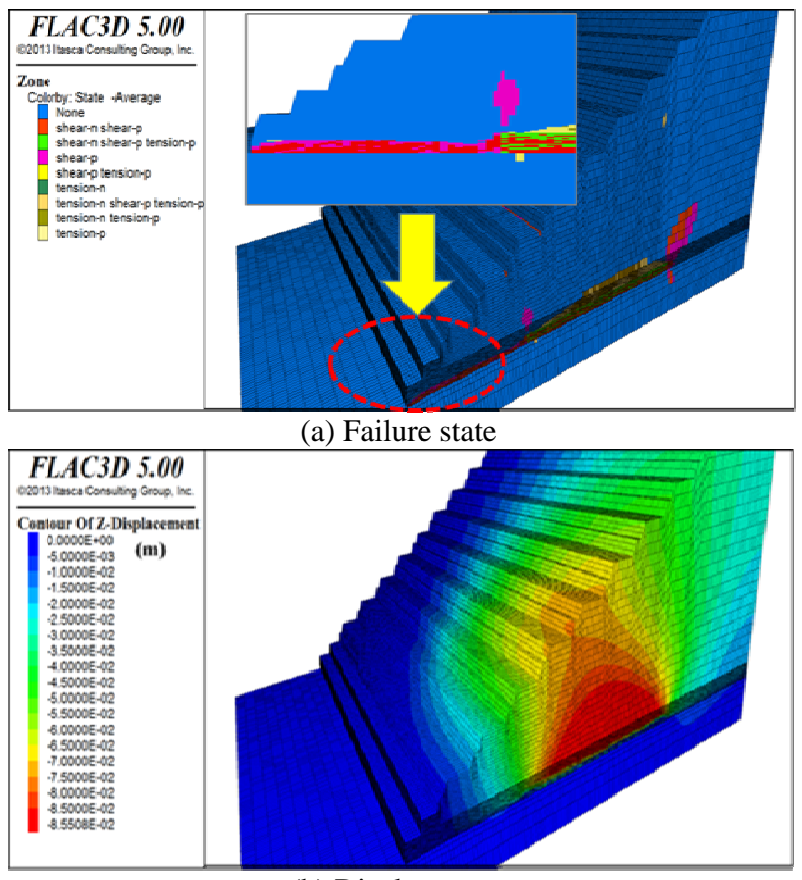

(b) Displacement

Fig. 10 Failure states and contours of displacement after extracting 2nd slices in $\mathbf{4 0 0} \mathbf{m}$ deep pit slope (boundary pillar width $=200 \mathrm{~m}$, inter-panel pillar width $=60 \mathrm{~m}$, panel width $=100 \mathrm{~m}$ ).

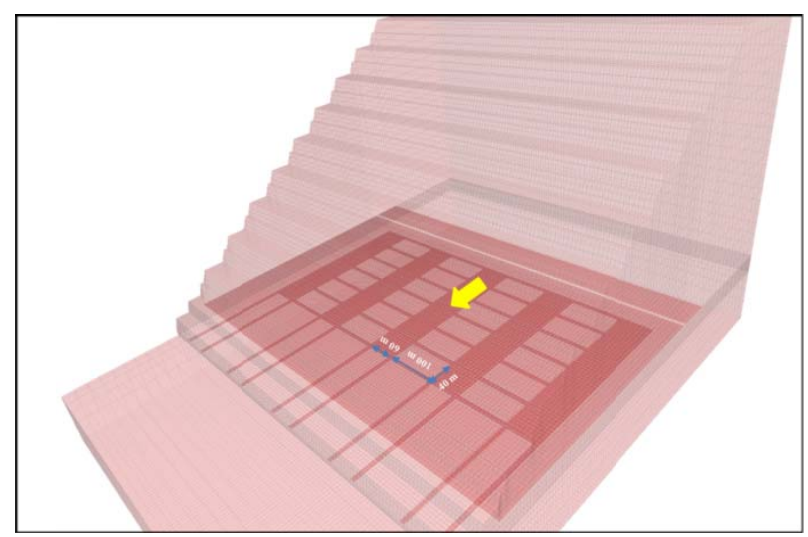

Fig. 11 Layout of panel modeled in the analyses for $400 \mathrm{~m}$ deep pit slope (boundary pillar width $=200 \mathrm{~m}$, panel width = $60 \mathrm{~m}$, inter-panel pillar width $=100 \mathrm{~m}$ ). 


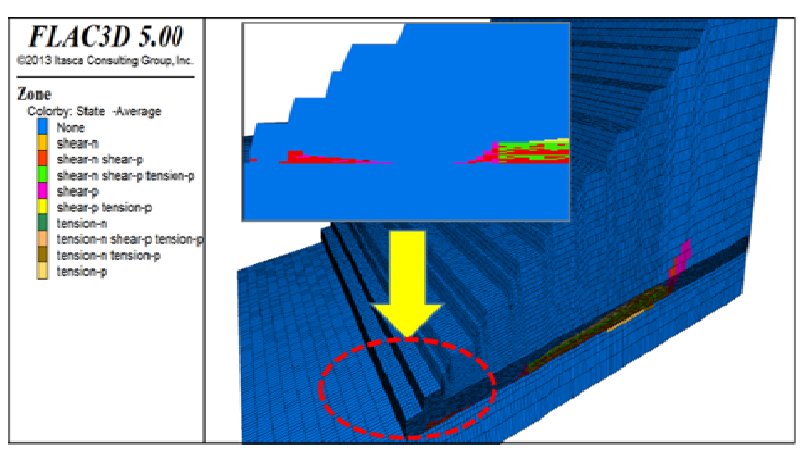

(a) Failure state

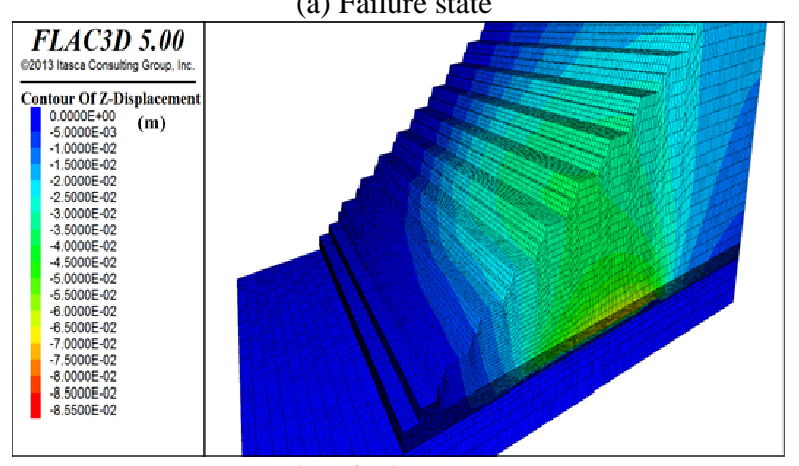

(b) Displacement

Fig. 12 Failure states and contours of displacement after extracting 2nd slices in $400 \mathrm{~m}$ deep pit slope (boundary pillar width $=200 \mathrm{~m}$, inter-panel pillar width $=100 \mathrm{~m}$, panel width $=60 \mathrm{~m})$.

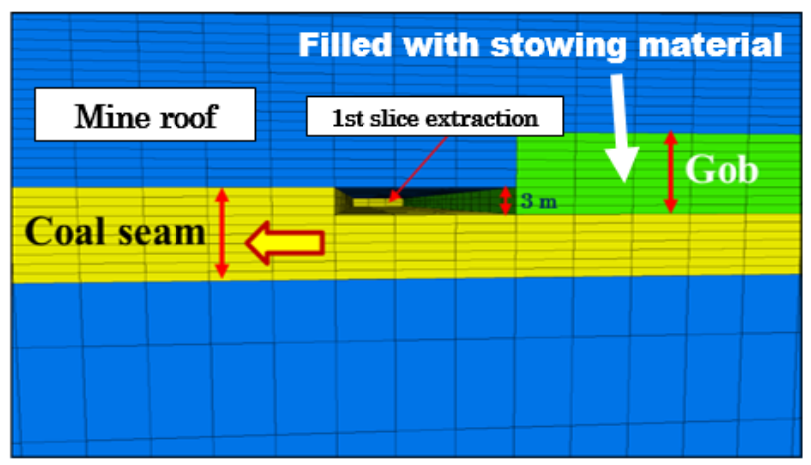

(a)The First slice extraction

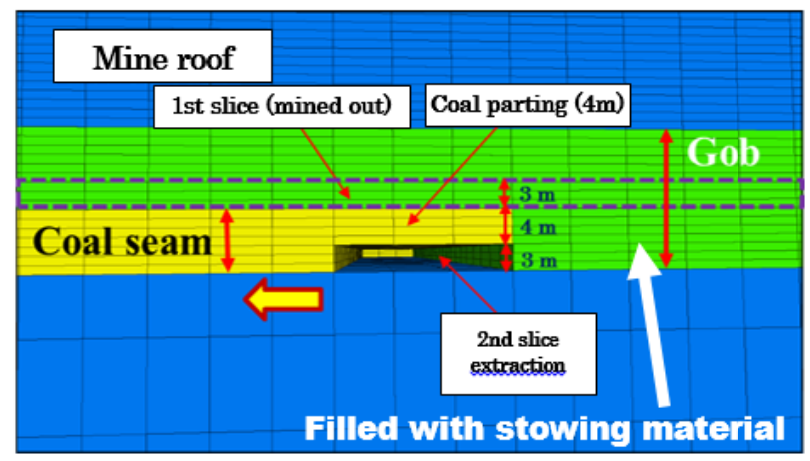

(b) The second slice extraction

Fig. 13 Scheme of multi-slicing performed in the analyses (with stowing). recovery will be decreased. Therefore, the application of multi-slice top coal caving in conjunction with stowing method is investigated and discussed.

The first slice is also extracted with conventional cut with $3 \mathrm{~m}$ mining height and stowing is injected into the gob immediately. After extracting and stowing the first slice, next slice extractions were conducted by applying longwall top coal caving method with leaving top coal $4 \mathrm{~m}$ thickness and cutting height of $3 \mathrm{~m}$ in second slice. Stowing is followed after each face advance as the same manner as in the first slice (see Figs. 13a-13b).

In the analyses, the panel and pillar sizes are initially designed as $100 \mathrm{~m}$ and $60 \mathrm{~m}$ as shown in Fig. 6 and the boundary pillar width is taken as $100 \mathrm{~m}$ for $200 \mathrm{~m}$ deep pit, whereas $200 \mathrm{~m}$ for $400 \mathrm{~m}$ deep pit. A flyash cement is taken as the slurry stowing material.

The mechanical properties of this stowing material used in the analyses are: density $1,000 \mathrm{~kg} / \mathrm{m}^{3}$, Poisson's ratio 0.23 , Young's modulus $617 \mathrm{MPa}$, tensile strength $0.5 \mathrm{MPa}$, cohesion 0.5 MPa, friction angle 26 degrees, respectively.

At first, the performance of stowing is investigated in the $200 \mathrm{~m}$ deep pit. Fig. 14 shows failure states and contours of displacement after extracting second slice with multi-slice top coal caving with stowing. It is found that failure zone around the mine roof becomes to be small dramatically and the displacement is decreased from $6.5-7 \mathrm{~cm}$ into $2.5-3 \mathrm{~cm}$. Since the subsidence at the slope is very small, the subsequent effect of subsidence at the slope such as failure, crack or sliding of slope will not be expected.

Figs. 15a-15b show failure states and contours of displacement after extracting second slice in $400 \mathrm{~m}$ deep pit. No failures are found in the boundary pillar and the displacement at the slope is small and about 3-3.5 cm after stowing even the panel size increases from $60 \mathrm{~m}$ to $100 \mathrm{~m}$ and the panel size increases from $60 \mathrm{~m}$ to $100 \mathrm{~m}$. Hence, the application of stowing system can not only improve the stability of slope and but also increase coal recovery. 


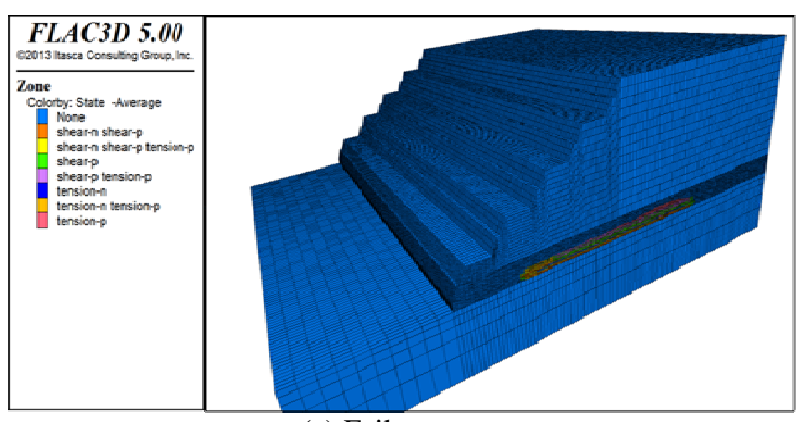

(a) Failure state

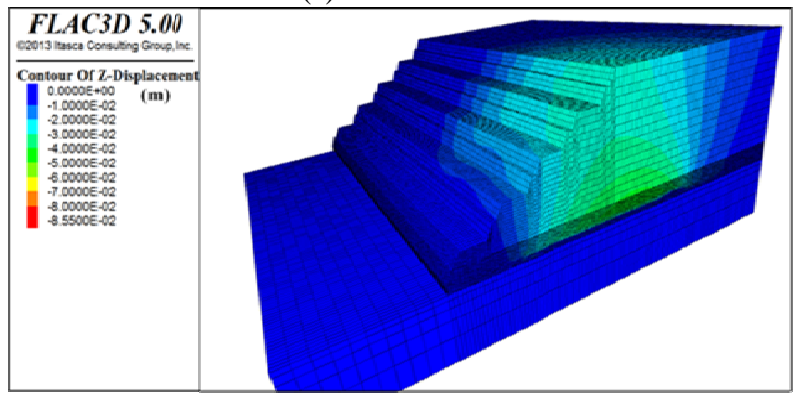

(b) Displacement

Fig. 14 Failure states and contours of displacement after extracting 2nd slices in $200 \mathrm{~m}$ deep pit slope (boundary pillar width $=100 \mathrm{~m}$, inter-panel pillar width $=60 \mathrm{~m}$, panel width $=100 \mathrm{~m})$.

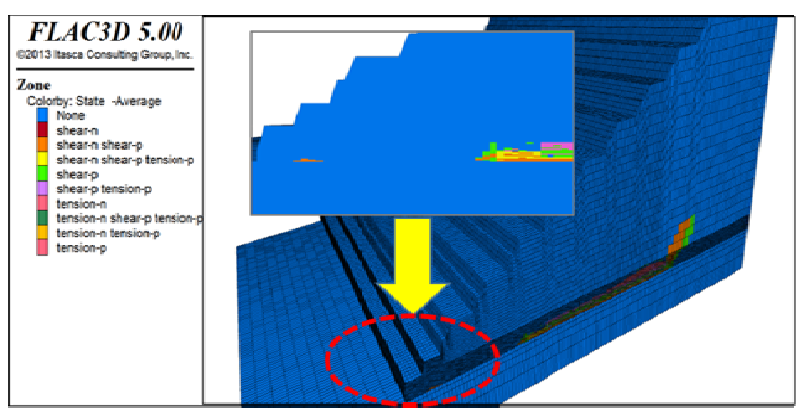

(a) Failure state

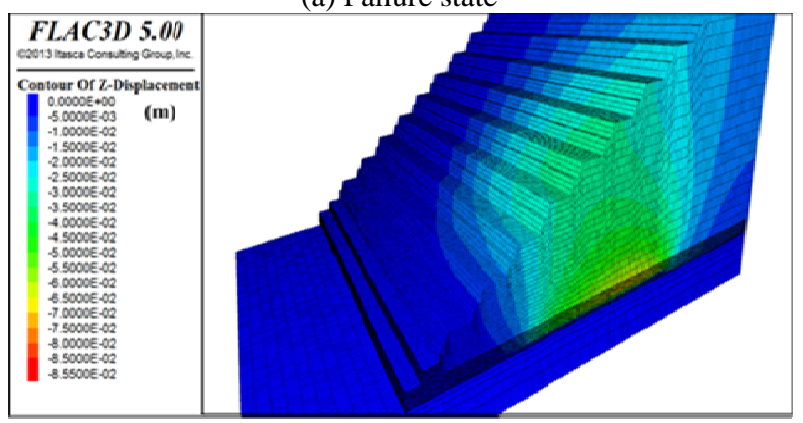

(b) Displacement

Fig. 15 Failure states and contours of displacement after extracting 2nd slices in $400 \mathrm{~m}$ deep pit slope (boundary pillar width $=200 \mathrm{~m}$, inter-panel pillar width $=60 \mathrm{~m}$, panel width $=100 \mathrm{~m})$.

From the above discussions, it can be concluded that the stowing is effective method for prevent the failure of pillars and control the displacement at the slope. In comparison with previous results without stowing, the boundary pillar width $200 \mathrm{~m}$ need to be left in order to be in stable and to have safe operation in $300 \mathrm{~m}$ deep pit. If stowing is applied, the boundary pillar width of $100 \mathrm{~m}$ is enough although the size of panel and inter-panel pillar sizes are the same. In $400 \mathrm{~m}$ deep pit, even though the boundary pillar of $200 \mathrm{~m}$ width still has to be left, the panel width to inter-panel pillar ration can be increased. For example, in the case of $400 \mathrm{~m}$ deep pit, the ratio of the width of panel to inter-panel pillar is approximately $0.60: 1$ when without stowing. However, if stowing is applied, the ratio of the width of panel to inter-panel pillar is approximately $1.67: 1$ when stowing is applied. In addition, since longer extraction length can be set, the productivity will also be higher.

\section{Conclusions}

The applicability of punch multi-slice top coal caving method for thick coal seams in different pit depths under weak geological conditions and appropriate design of boundary pillars, inter-panel pillars and panels are investigated and discussed in this paper. Moreover, the application of multi-slice top coal caving in conjunction with stowing for weak and thick seam is proposed and discussed in order to increase the coal recovery and improvement of stability of slope. It is found that stowing is quite effective to prevent the pillar failure and to control the stability and subsidence at the slope. As the results, the coal recovery can be improved.

However, in order to develop the appropriate design of punch multi-slice top coal caving method under weak geological condition, the more study have to be conducted including the control of top coal caving, the stowing material, sizes of panel/pillar, mining sequence, etc.

\section{References}

[1] Oya, J., Shimada, H., Sasaoka, T., Ichinose, M., Matsui, K., Pertiwi, R., and Fajrin, A. M. 2009. "Fundamental Study 
on AMD-prevention by Compacted Waste Rocks at Berau Coal Mine, Indonesia." In Proceedings of the 2nd International Symposium on Novel Carbon Resource Science, IV19-IV24.

[2] Inoue, N., Hamanaka, A., Matsumoto, S., Shimada, H., Sasaoka, T., and Matsui, K. 2014. "Effective Assessment Methods of Soil Erosion Control in Indonesian Open Pit Mine.” In Proceedings of 18th Conference on Environment and Mineral Processing, 221-7.

[3] Matsui, K., Sasaoka, T., Shimada, H., Furukawa, H. Takamoto, H., and Ichinose, M. 2010. "Some Consideration in Underground Mining Systems for Extra-thick Coal Seam.” In Proceedings of the 3rd International Symposium on Mineral Resources and Mine Development, 355-68.

[4] Hamanaka, A., Sasaoka, T., Shimada, H., Matsui, K., and Takamoto, H. 2011. "Application of Punch Mining System to Indonesian Coal Mining Industry.” In Proceedings of the 20th International Symposium on Mine Planning and Equipment Selection, 187-97.

[5] Shibata, S., Lin, N. Z., Shimada, H., Hamanaka, A., Sasaoka, T., Matsui, K., and Lawowattanabandit, P. 2013. "Preliminary Study on Design of Longwall Mining from Final Highwall at Mae Moh Lignite Mine in Thailand.” In
Proceedings of the 22nd Mine Planning and Equipment Selection, 227-34.

[6] Sasaoka, T., Shimada, H., Takamoto, H., Hamanaka, A., and Matsui, K. 2012. "Development of Underground Coal Mine from Open Cut Highwall in Indonesia." In Proceedings of 5th International Symposium on High Performance Mining, 495-510.

[7] Robertson, B. W., O’ Regan, G., and McKew, M. 1988. “Longwall Punch Mining from Open Cut Highwalls.” In Proceedings of the AUSIMM Illawara Branch 21st Century Higher Production Coal Mining Systems, 215-20.

[8] Macdonald, S., and Hill, D. 2008. "Practical Strata Management, Beltana No. 1 Mine, Australia.” In Proceedings of 27th International Conference on Ground Control in Mining, 275-83.

[9] Hill, D., and MacKinnon, M. 2011. "Case Study of Roof Behavior and Conditions for Longwall Face Recoveries at Beltana No. 1 Mine, Australia.” In Proceedings of 30th International Conference on Ground Control in Mining, 265-70.

[10] Hem, P. 2012. "Pits \& Quarries.” In Techno Mine. Accessed October 25, 2014.http://technology.infomine.com/reviews/pitsandquar ries/welcome.asp?view=full. 